\title{
Nonferrous Materials Extraction from Heavy Oil with Using Electro Activated Water-Salt Solutions
}

\author{
RASHID I. BATKAYEV ${ }^{1 *}$, ASIYA F. BATKAYEVA ${ }^{1}$, NIKOLAY N. ZOBNIN ${ }^{1}$ \\ and ANASTASSIYA.Y. KOVALEVA ${ }^{1}$
}

\author{
M. Au ezov South Kazakhstan State University, Kazakhstan, 160000, \\ Shymkent, Tauke khana venue, 5. Kazakhstan. \\ *Corresponding author E-mail: anastasiya2301@mail.ru
}

http://dx.doi.org/10.13005/ojc/330562

(Received: July 22, 2017; Accepted: August 15, 2017)

\begin{abstract}
This article is devoted to development of theoretical basis for the non-reagent dementalization of high-viscosity oils in the process of demineralization and dehydration of oil in fields for the extraction of non-ferrous metals, as well as to exclude the negative influence of metals on the depth of oil refining, the durability of catalysts, the efficiency of refining processes and the quality of oil products. The results of analysis of the current-voltage characteristic proved that all values of the electrical characteristics of the above process are interrelated. Also, a determination was made of the optimal operating conditions of the device for obtaining productive solutions. During the research it was found out that the kinetics of the oxidative decomposition of vanadocene dichloride is accelerated by a specific acidic electrophilic catalysis in which there is a rapid emerging of all protolytic equilibrium in the solution and the subsequent slow transformation of the protonated reagent in the reaction products
\end{abstract}

Key words: Vanadium, Electro activated water solution, Heavy oil, Metal, Demetallization, productive solution.

\section{INTRODUCTION}

The task of improving the processes of oil refining necessitates the use of all its components, including microelements. On the one hand, heteroatomic oil compounds can be considered as a potential source of raw materials for various industries, on the other - heteroatomic compounds and trace elements of oil negatively affect the indicators of oil refining and petrochemical processes, impair the quality of marketable products.

The presence of metals in petroleum feed stocks is undesirable for two reasons. First, in the catalytic processing of raw materials, metalcontaining compounds are destroyed, and the released metals are deposited in the pores of the 
catalysts and irreversibly deactivate them. Secondly, when burning heavy oil residues as boiler fuels, vanadium pentoxide $\left(\mathrm{V}_{2} \mathrm{O}_{5}\right)$ is formed - a very corrosive-active component of ash that causes corrosion of boiler and other equipment. The presence of metals in petroleum coke for metallurgy and the production of graphite products adversely affects the products of these industries ${ }^{1,2}$.

The concentrations of metals $\mathrm{V}, \mathrm{Ni}$ in the oil of some deposits are so significant that they are quite comparable with the metal content in ores, and their production from oil is quite cost-effective and economically justified.

At the same time, practice proves that with the existing technological schemes of oil processing, a large number of useful components (gold, zinc, copper, nickel, vanadium, etc.) that are mined along with oil are lost. This also leads to a decrease in the quality of oil, undesirable ecological displacements of natural equilibrium when metals fall into oil products. In this regard, the search for innovative schemes for the preparation and processing of oil with the extraction of associated metals is an actual scientific problem of the modern oil and gas industry and in particular, oil refineries (refineries). In addition, the selling price of oil does not take into account the cost of oil contained in oil, due to the lack of technology for extracting metals from oil, which causes great losses for the country's oil and gas industry as a whole $e^{3,4}$.

The universality of electrochemical activation technology is associated with the possibility of using the same technological processes for the synthesis of electrochemically active solutions, as well as technical systems with the same type of electrochemical reactors for use in various industries. The technique and technology of electrochemical activation can be effectively used by the widest range of consumers.

The scientific novelty of functional and technical solutions is based on the use of the synthesis mechanism when imposing physical influences, including and electric to aqueous solutions. The mechanism of changing the characteristics of salt solutions is due to the fact that when an electric field is applied in the presence of salts, the aqueous solutions become metastable (activated) state, which is characterized by abnormal physicochemical characteristics (oxidationreduction potential, associated with the activity of electrons in water, $\mathrm{pH}$, electrical conductivity, changes in water structure) that persist for a long time. The actual use of electrochemically activated solutions is due to the low cost of the solutions obtained. Such substances can be obtained only by using an electrochemical conversion.

\section{MATERIAL AND METHOD}

In the researchvarious variants of connecting the electrical circuit of a cell to obtain leach solutions were investigated:

- $\quad$ obtaining a leach solution using an electrical circuit of reduced voltage using salts, in particular sodium chloride, without the use of sulfuric acid;

the use of a leaching solution, using an electrical circuit using an increased voltage without the use of sodium chloride and without the use of sulfuric acid.

The combinations of the above schemes were used on the same cell with different connections. Experiments were carried out on a pilot plant with various options for power and load connections.

The diaphragm consisted of belting fabric (an option made of ceramics based on aluminum oxides). In the variant with a diaphragm of belting fabric, a bag with a diameter of $75 \mathrm{~mm}$ with a volume of $750 \mathrm{ml}$ was used. Cathode electrode was made of $2 \mathrm{~mm}$ stainless steel with a diameter of $190 \mathrm{~mm}$, a height of $190 \mathrm{~mm}$. The anode was also constructed of stainless steel $2 \mathrm{~mm}$ in the form of a triangle with a long side of $30 \mathrm{~mm}$ and a height of $180 \mathrm{~mm}$;

The device functions on the basis of two power supply circuits:

- $\quad$ on the bridge scheme;

- device with an inverter, which allows to convert the frequency of the output voltage.

The intensity of the process is maintained due to the channeled motion of anions relative to the interelectrode space from the top of the cathodes located orthogonally to the anode, which ensures 
intensive local anion release in the corresponding zones of the anode and intensive removal of water from the incoming water molecules and dense flow of the next anions in the channel. In addition, the hydrated shells of mineralized particles at the moment of impact of the latter on the anode surface are intensely saturated by adsorption with an atomic oxidizer and, due to the conical shape of the reactor, move to the upper part of the cone along a vortex trajectory, rapidly removing the reagent from the anode and ultimately saturating the solution, which leads to the maximum efficiency of the reextraction of vanadium and other useful elements by the atomization method in the upper part of the cone.

\section{RESULTSANDDISCUSSION}

At the first stage of the research, the testing of the modular unit was conducted in the mode of an electric circuit of reduced voltage, using salts, in particular sodium chloride, using a bridge circuit of the device. The experimental data are presented in the form of graphs in Pic. 1.The salt content in the electrolyte was 0.1 to $24 \%$, and the maximum salt content, in particular sodium chloride, was $24 \mathrm{~g} / \mathrm{l}$. Initially, the effect of the $\mathrm{pH}$ of the solution was researched depending on the content of sodium chloride in the solution. The experiments were performed with a change in the activation time from 0 to $2 \mathrm{~min}$. (1) and from 0 to $3 \mathrm{~min}$. The initial $\mathrm{pH}$ of the solution was 5.Experimental data showed that when the concentration of salts in a solution increases from 1 to $20 \%$, the following processes occur.

At a concentration of $1 \mathrm{~g} / \mathrm{I}$, the $\mathrm{pH}$ of the salt solutiondecreases sharply to 2.4 at $2 \mathrm{~min}$. and $\mathrm{pH}$ is 1,8 at $3 \mathrm{~min}$. A further increase in the concentration of salts in the electrolyte to $5 \mathrm{~g} / \mathrm{l}$ leads to a decrease in the $\mathrm{pH}$ of the solution to 1.8 at two min. and $\mathrm{pH} 1.4$ at three $\mathrm{min}$. With an increase in salt concentration in the electrolyte up to $16 \mathrm{~g} / \mathrm{l}$, practically does not affecton the $\mathrm{pH}$ of the activated solution and it is 1.3 at two $\mathrm{min}$. and $\mathrm{pH}$ is 1.34 at 3 min.. Numerical values of the dependence of the $\mathrm{pH}$ solution upon completion of the electroactivation process on the concentration of salts are given in the table 1.

Further increase of salts in the solution does not lead to a decrease in the $\mathrm{pH}$ of the salt solution. Thus, it can be concluded that the minimum $\mathrm{pH}$ of salt solution is 1.3 , as in two and three min. of the process.

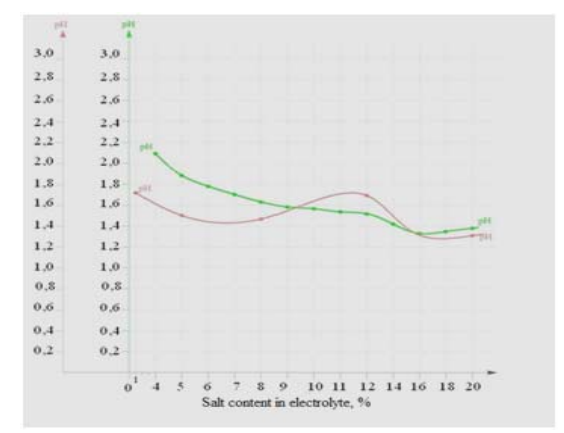

Time of electroactivation: red line - 3 minutes, green line - 2 minutes

Fig. 1. Dependence of the $\mathrm{pH}$ solution upon completion of the electroactivation process on the concentration of salts

Depending on the mode of electrochemical effect and the content of sodium chloride in the initial solution, the $\mathrm{pH}$ of the catholyte usually ranges from 7 to 12 , and the $\mathrm{pH}$ of the anolyte is from 2 to 7 . In this research an anolyte will beused.Oxidation-reduction potential, which characterizes the oxidizing ability to the activated solution, in an anolyte from 400 to $1200 \mathrm{mV}$, which is higher than that of catholyte.In addition, a low $\mathrm{pH}$ value of the anolyte promotes retention of the reoxidated metal ions in the aqueous phase. On the other hand, low $\mathrm{pH}$ contributes to the stabilization of the water-oil emulsion, which can lead to

Table. 1 : Dependence of the $\mathrm{pH}$ solution upon completion of the electroactivation process on the concentration of salts

\begin{tabular}{lcccccccc}
\hline \multicolumn{10}{c}{ Value } \\
\hline Characteristic & \multicolumn{10}{c}{$\begin{array}{c}\text { 1 } \\
\text { Salt content in electrolyte, \% }\end{array}$} & 0.1 & 1 & 2 & 3 & 5 & 15 & 20 & 24 \\
$\mathrm{pH}$ level & 5.00 & 2.40 & 1.80 & 1.40 & 1.30 & 1.30 & 1.32 & 1.34 \\
\hline
\end{tabular}


problems in the separation of the emulsion. Therefore, during the selection of volt-ampere parameters of the process of electroactivation, it is necessary to balance the optimal parameters of the individual stages of the process.

The productivity of the enlarged-laboratory device for unipolar electrochemical treatment of water and aqueous solutions was from 0.1 to 0.5 cubic meters per h. Experimentally, it was revealed that electrochemical reactors with plane-parallel electrodes are suitable for electrochemical treatment of water and solutions with mineralization from 10 to $25 \mathrm{~g} /$. Experience has shown that electrochemical systems for producing activated water can work satisfactorily in a specific technological process and only under the conditions that were fixed during the design, and even relatively small changes in the mineralization of the source water, the flow of ready solutions, the hydraulic connection scheme, and other operating conditions lead to a significant loss of efficiency of the technological process as a whole.

\section{CONCLUSIONS}

The carried out analysis of the current-voltage characteristic proved that all values of the electrical characteristics of the above process are interrelated. Also, a determination was made of the optimal operating conditions of the device for obtaining productive solutions.

As it is obviously from the results of research the kinetics of the oxidative decomposition of vanadocene dichloride, this process is accelerated by a specific acidic electrophilic catalysis in which there is a rapid emerging of all protolytic equilibrium in the solution and the subsequent slow transformation of the protonated reagent in the reaction products.

The results presented in this article was obtained in the framework of implementationof the project of the Ministry of Education and Science of the Republic of Kazakhstan No1604/ГФ4 «Extraction of non-ferrous metals from high-typed oils with application of electroactivated water-soluble solutions».

\section{REFERENCES}

1. Batkayev, R.I.;Nugmanov, A.A. Development of complex technologies for recycling of technogenic wastes. 2006, 32.

2. Vysotskaya, N.A., Kabylbekova, B. and others. Role of components containing in water on the formation corrosion - scale deposits in pipelines of heating system, Oriental Journal of Chemistry. 2015, 261-269.

3. Lorber,C.'Vanadium Organometallics." Chapter 5.01. Comprehensive Organometallic Chemistry III. Elsevier. 2007, 1-60.

4. Elschenbroich, C.: Organometallchemie. B. G. Teubner Verlag. 2008, 50.

5. Arens,V.Zh.Physical-chemical geo-technology. Editions of MSGU. 2001, 656.

6. Goldberg, I.S.; Kaplan, Z.G.;Ponomarev V.S. Soviet geology. 1986, 100.

7. Bakhir, V.M.;Vtorenko, V.I. and others. Economic application prerequisites of "STEL" installations in therapeutic for synthesis, disinfection and sterilizing solutions. 2004, 27

8. Kopf-Maier, P.; Kopf, H. Vanadocendichlorideinweiteres Antitumor-Agensaus der Metallocen-reihe. 1999, 805-807.

9. Nadirov, N.K.;Kotova, A.V.;Kamyanov, V.F.
New oil of Kazakhstan and their use: Metals in oil. Alma-Ata.1984, 448.

10. Akhmedzhanov, T.K.;Nuranbayev, G. and others. Patent RK 25065 dated 15.11.2011. Inventor's certificate 2010/1293.1, publ. in 11, dated 15.12.2012, 2012.

11. Batkayev, R.I.;Nugmanov,À.À. Development of complex technologies for recycling of technogenic wastes. 2006, 32

12. Beysenbayev, O.K.; Isa, A.B.;Kovaleva A.Y. Research of Polyacrylonitrile Saponification Heterophase Process Mechanism in Different Conditions. Oriental Journal of Chemistry. 2015, 4-9.

13. Vysotskaya, N.A.;Kabylbekova B. and others. Role of components containing in water on the formation corrosion - scale deposits in pipelines of heating system. Oriental Journal of Chemistry. 2015, 261-269.

14. C. Lorber: "Vanadium Organometallics." Chapter 5.01. Comprehensive Organo metallic Chemistry III. Elsevier. 2007, 1-60.

15. Christoph Elschenbroich: Organo metall chemie. B. G. Teubner Verlag. 2008, 50. 